\title{
Operações Urbanas Consorciadas em Balneário Camboriú: o desvirtuamento do solo criado
}

\author{
Urban Consortium Operations in Balneário Camboriú: \\ the distortion of the principle of solo criado
}

\author{
Marina Toneli Siqueira [I] \\ Carolina Silva e Lima Schleder [II]
}

\section{Resumo}

Operações urbanas consorciadas (OUC) foram popularizadas nos planos diretores pós-Estatuto da Cidade, principalmente pela promessa de convergir interesses públicos e privados na implantação de grandes projetos urbanos. 0 instrumento baseia-se no princípio do solo criado, compartiIhando custos e benefícios do desenvolvimento urbano e regularizando a oferta de incentivos ao mercado imobiliário por meio de contrapartidas. Entretanto, seus resultados são polêmicos e ainda pouco explorados em municípios de menor porte. 0 caso de Balneário Camboriú, objeto desta pesquisa, demonstra o desvirtuamento do solo criado ao permitir a utilização do potencial construtivo gerado pela OUC fora de seu perímetro. Consolidando frentes de expansão imobiliária, o instrumento vem colaborando com a verticalização local e pouco gerou de contribuições para a cidade como um todo.

Palavras-chave: solo criado; operações urbanas consorciadas; planos diretores; estatuto da cidade; Balneário Camboriú/SC.

\begin{abstract}
Urban Consortium Operations (UCO) were popularized in Brazilian master plans after the enactment of the City Statute, mainly because of their promise of converging public and private interests in the implementation of large urban projects. This instrument is based on a principle known as solo criado: the separation between building rights and property rights, distributing the costs and benefits of urban development and regularizing the offer of incentives to the real estate market by demanding counterparts. Nevertheless, its results are polemical and have been little explored in smaller municipalities. The case of Balneário Camboriú (Southern Brazil), the object of this research, demonstrates the distortion of the solo criado principle by allowing the utilization of the construction potential generated by the UCOS outside the perimeter of the projects. Consolidating real estate expansion fronts, the instrument contributes to local high-rise building and has not generated many benefits to the city as a whole.
\end{abstract}

Keywords: solo criado; urban consortium operations; master plans; City Statute; Balneário Camboriú/State of Santa Catarina. 


\section{Introdução}

Operações Urbanas Consorciadas (OUCs) são parcerias público-privadas para a implementação de grandes projetos urbanos. Por um lado, elas objetivam realizar transformações urbanísticas estruturais, melhorias sociais e valorização ambiental a partir da venda de benefícios construtivos. Por outro, esses benefícios construtivos significam a modificação de índices e características de parcelamento, uso e ocupação do solo; alterações das normas edilícias; regularização de construções, reformas ou ampliações; entre outros. A utilização de formas similares de parcerias público-privadas no desenvolvimento urbano antecede o Estatuto da Cidade. No entanto, a lei federal regulamentou esse instrumento e expandiu sua utilização para cidades de menor porte. Assim, se a obrigatoriedade da elaboração de planos diretores para municípios com mais de 20.000 habitantes, entre outros, aumentou a utilização dos instrumentos do Estatuto nos municípios brasileiros, este também parece ser o caso das OUCs.

A perspectiva do cumprimento de uma agenda de interesses públicos a partir de recursos que seriam outrora capturados privadamente é o aspecto mais destacado das OUCs. Entretanto, o controle social, o equilíbrio da expansão urbana e o atendimento obrigatório das populações diretamente atingidas pelo projeto são alguns de seus aspectos mais polêmicos. Entre as OUCs mais conhecidas restam dúvidas sobre os seus reais beneficiários e se elas não seriam somente operações imobiliárias. Para além das grandes metrópoles nacionais, no entanto, ainda falta avaliar a sua capacidade de implementação em cidades com porte menor, bem como o impacto nelas gerado. Nesta pesquisa, analisamos o caso de Balneário Camboriú e das três OUCs já implantadas na cidade.

Localizada no litoral norte de Santa Catarina, Balneário Camboriú é conhecida, entre outros aspectos, pelas belezas naturais que atraem os turistas e pelo skyline peculiar com algumas das edificações mais altas do País, resultado da legislação urbana permissiva, do mercado imobiliário ativo e do grande número de segundas-residências e unidades para aluguel, entre outros. O Plano Diretor atual da cidade, elaborado em 2006, é o primeiro a introduzir os instrumentos do Estatuto da Cidade e as operações urbanas. Desde então, foram implantadas três OUCs na cidade, com resultados práticos passíveis de análise. Para tanto, este trabalho realizou análise de documentos do plano diretor e legislações específicas; pesquisa de arquivo com os dados disponibilizados pela Prefeitura Municipal de Balneário Camboriú; mapeamentos espaciais e visitas a campo. Como resultado, tem-se uma análise crítica do instrumento e de suas possibilidades de aumento do potencial construtivo na cidade como um todo, ao permitir a utilização dos incentivos ao mercado imobiliário fora do perímetro original do projeto.

Para explicar esse impacto das OUCs, 0 artigo está organizado em cinco seções incluindo a presente introdução e as considerações finais. Na próxima seção, o instrumento OUC é identificado a partir do princípio do solo criado e do compartilhamento das responsabilidades do desenvolvimento urbano. Para além das grandes metrópoles nacionais, a terceira seção apresenta a cidade de Balneário Camboriú e a história de seu planejamento urbano, em especial o plano diretor atual da cidade que introduz as OUCs localmente. Na quarta 
seção, as três OUCs são analisadas em seus aspectos normativos, funcionamentos efetivos e impactos sociais. Destaca-se que, embora os recursos arrecadados tenham sido utilizados no perímetro e nas obras previstas nas leis específicas, a conversão dos Cepacs (Certificados de Potencial Adicional de Construção) em benefícios construtivos pode ser realizada em localizações fora do projeto e, portanto, em desacordo com o Estatuto da Cidade. Como considerações finais, a experiência de Balneário Camboriú demonstra o desvirtuamento do princípio do solo criado, uma vez que o uso mais intensivo do solo não é gerado na mesma localização dos investimentos das OUCs. Ainda, os investimentos são majoritariamente obras viárias, resultando em poucos benefícios para a cidade como um todo ou que atinjam os objetivos mais amplos de melhorias sociais e/ou valorização ambiental, tal como previsto pelo Estatuto da Cidade.

\section{As OUCs e o compartilhamento das responsabilidades pelo desenvolvimento urbano}

O Estatuto da Cidade (lei federal n. 10.257 de 2001) representa uma conquista para o planejamento urbano brasileiro. Nosso processo de urbanização produziu problemas urbanos intensos e com seus efeitos mais perversos recaindo naqueles grupos socialmente vulneráveis. São cidades marcadas pela desigualdade e segregação socioespacial; pelo déficit habitacional e pela habitação precária; pelos problemas de mobilidade e pela falta de infraestrutura urbana no geral; pela degradação ambiental e destruição do patrimônio histórico (material e imaterial); pelo desrespeito à legislação urbanística e aos códigos de obras que atinge todos os grupos sociais e produz uma cidade muito diversa daquilo que foi efetivamente planejado. De fato, a história do planejamento urbano brasileiro e nosso processo de urbanização são bastante diversos e, para que isso não aconteça com o legado do Estatuto da Cidade, é preciso avaliar sua implementação e os impactos gerados por seus instrumentos localmente (Villaça, 1999; Maricato, 2000).

Depois do histórico do movimento pela reforma urbana e da longa discussão por uma solução pactuada (Bassul Jr., 2002), a aprovação do Estatuto da Cidade, em 2001, respondeu à demanda por uma legislação federal de planejamento urbano baseada nos princípios da função social da cidade e da propriedade e de sua gestão democrática a partir da participação social. Alguns dos instrumentos previstos são obrigatórios, como a elaboração de planos diretores participativos para as cidades com mais de vinte mil habitantes e pertencentes a regiões metropolitanas, entre outros critérios. Entretanto, a maior parte dos instrumentos previstos é de ordem facultativa, e cabe aos municípios, como entes federativos responsáveis pela política urbana, avaliar a pertinência e a implementação deles. Esse é o caso das OUCs.

As operações urbanas são definidas pelo Estatuto da Cidade como

o conjunto de intervenções e medidas coordenadas pelo Poder Público municipal, com a participação dos proprietários, moradores, usuários permanentes e investidores privados, com o objetivo de alcançar em uma área transformações urbanísticas estruturais, melhorias sociais e a valorização ambiental. (Brasil, 2001) 
Entretanto, a sua utilização é anterior à legislação federal, com casos em São Paulo, Belo Horizonte, Recife e Natal abrindo o debate sobre o balanceamento do desenvolvimento urbano a partir do compartilhamento dos custos da implementação de grandes projetos urbanos. Esse compartilhamento é realizado com a definição de um plano urbanístico para um perímetro específico no qual benefícios são outorgados e contrapartidas são esperadas dos investidores privados. Por um lado, entre os benefícios podem estar previstas a modificação de índices e características de parcelamento, uso e ocupação do solo e subsolo, bem como alterações das normas edilícias; a regularização de construções, reformas ou ampliações; e a concessão de incentivos a operações urbanas que utilizam tecnologias visando à redução de impactos ambientais. Por outro, as contrapartidas podem exigir obras diretas, o pagamento de outorga onerosa ou a compra de certificados financeiros equivalentes aos benefícios construtivos ofertados, os Certificados de Potencial Adicional de Construção (Cepacs). Os recursos arrecadados somente podem ser utilizados na própria OUC, fazendo deste o princípio mais atrativo do instrumento: a sua viabilidade econômica ou ao menos a possibilidade de realizar uma agenda pública com menor custo aos cofres municipais. Dessa forma, as OUCs realizariam a captura da "mais-valia fundiária" gerada pelos investimentos públicos (Santoro, 2004; Smolka, 2014).

Os investimentos públicos e privados realizados em uma OUC têm um efeito direto na valorização dos produtos imobiliários localizados em seu perímetro e entorno. Se é fato que terrenos de mesmo tamanho e condições de construção podem atingir preços diversos se localizados em contextos urbanos diferentes, a sua localização é um fator fundamental na sua valorização. Embora condições naturais possam garantir o monopólio de vistas privilegiadas e acesso a recursos, a localização é um produto criado histórica e coletivamente a partir de investimentos públicos e privados na produção do espaço urbano. Portanto, se em um plano urbanístico estão previstas "transformações urbanísticas estruturais, melhorias sociais e a valorização ambiental", como objetiva as OUCs, de acordo com o Estatuto da Cidade (Brasil, 2001), está claro que haverá a valorização das propriedades incluídas no perímetro e no entorno imediato de uma operação. Além disso, se essas obras são majoritariamente públicas, isso significa que investimentos realizados pelo Estado estão sendo apropriados privadamente por proprietários fundiários e agentes imobiliários e, não à toa, existem tantas acusações de favorecimentos e corrupção no processo de desenvolvimento urbano brasileiro.

Ainda, um outro impacto na valorização dos terrenos é arcado com recursos públicos: o uso mais intensivo da terra urbana. Na legislação urbanística brasileira, a definição do uso e do que é possível construir em um terreno é dada pelo zoneamento e pelos índices urbanísticos, como o número máximo de pavimentos, pela taxa de ocupação do lote e, em especial, pelo coeficiente ou índice de aproveitamento. Esse coeficiente de aproveitamento é um valor numérico que, multiplicado pela área de um terreno, representa quantos metros quadrados é possível construir naquele mesmo terreno. Portanto, se o índice de aproveitamento é um, significa que somente é possível construir uma vez a área do terreno; se o índice é dois, duas vezes; e assim por diante. Qualquer índice acima de um, no entanto, significa construir mais do que a metragem original do terreno, ou seja, 
em um solo virtual e que foi criado pelos índices urbanísticos das leis de uso e ocupação do solo. Esse solo criado, como definido pelo Estatuto da Cidade, representa a possibilidade também de lucros maiores para investidores e proprietários imobiliários ao aumentar a área de construção final.

O solo criado, portanto, gera um uso mais intensivo do terreno, das infraestruturas e dos serviços urbanos. No processo de desenvolvimento urbano brasileiro, a responsabilidade na adequação dessa infraestrutura e dos serviços urbanos tem recaído majoritariamente sobre os órgãos públicos, e isso significa que é a sociedade brasileira como um todo que vem arcando com esses custos. No entanto, o Estatuto da Cidade permite a cobrança por esse uso mais intensivo do lote como forma de adequar infraestrutura e serviços urbanos, bem como investir no desenvolvimento urbano como um todo. Esse instrumento é conhecido como outorga onerosa do direito de construir (Osório, 2002).

Nesse sentido, o proprietário fundiário tem a propriedade de um terreno, e as leis de uso e ocupação do solo usualmente refletem essa propriedade ao garantir um direito de construção igual à área original do terreno, ou seja, um coeficiente de aproveitamento igual a um. Para construir acima desse coeficiente de aproveitamento básico, é necessário pagar pelo direito de construção e pelo uso mais intensivo do terreno, isto é, pelo solo criado. Finalmente, a outorga onerosa pode se referir à alteração de uso, também considerando a valorização esperada, a proporcionalidade entre a infraestrutura existente e o aumento de densidade esperada em cada área.

Em todas as situações, como imposto pelo Estatuto da Cidade, a fórmula de cálculo para a cobrança, os casos passíveis de isenção do pagamento da outorga e a contrapartida do beneficiário devem ser estipulados em lei municipal. Em se tratando de terrenos localizados em uma OUC, é aplicada uma outorga onerosa específica e diferente do resto da cidade.

Segundo o Estatuto da Cidade (Brasil, 2001), a OUC deve ser aprovada em uma lei específica na qual são expostos os objetivos da operação; a área a ser atingida e seu plano de ocupação; o estudo prévio de impacto de vizinhança; a forma de atendimento econômico e social para a população diretamente afetada pelo projeto; e uma forma de controle social da operação. Em especial, essa lei deve expor os incentivos e as contrapartidas esperadas dos proprietários, usuários permanentes e investidores privados. Podem estar previstos, como já mencionado, incentivos para a utilização de tecnologias visando à redução de impactos ambientais, a regularização de construções e a modificação de índices e características de parcelamento, uso e ocupação do solo e subsolo, bem como alterações das normas edilícias. Poderia ser possível, por exemplo, realizar a alteração de uso residencial para comercial, realizar remembramentos e desmembramentos e construir edificações mais altas, com maior ocupação do terreno e maior coeficiente de aproveitamento. Essas alterações nas normas urbanísticas na área da operação, assim como o seu plano de investimentos, resultariam na valorização imobiliária mencionada acima e naqueles ganhos apropriados privadamente e que, portanto, devem ser objeto de contrapartidas.

As contrapartidas de uma operação urbana podem ser obras diretas, como a adequação do sistema viário, a construção de uma praça ou de unidades de habitação de 
interesse social. Uma OUC também pode prever contrapartidas na forma de pagamentos financeiros, isto é, outorga onerosa do direito de construir e/ou de alteração de uso. Entretanto, ao invés dos recursos arrecadados irem para um fundo municipal de urbanização, eles devem ser utilizados obrigatoriamente no perímetro da OUC e para atingir os objetivos expostos na lei específica do projeto. Finalmente, as contrapartidas exigidas em uma OUC podem ser viabilizadas na forma de Cepacs, títulos financeiros que são convertidos nos benefícios construtivos no perímetro específico de uma operação e que podem ser comercializáveis publicamente em leilão e, posteriormente, em mercados secundários. Os recursos arrecadados também somente podem ser utilizados naquela mesma OUC e nos objetivos previstos em sua lei específica, como estipulado pelo Estatuto da Cidade.

Esse mecanismo de funcionamento das OUCs com a captura da valorização imobiliária ou do solo criado para o cumprimento de um projeto urbano específico faz com que o instrumento seja atraente para as municipalidades e venha se popularizando nos planos diretores pós-Estatuto da Cidade. Em pesquisa realizada com 526 leis de Planos Diretores de municípios de diferentes portes e estados no País, encontrou-se a incorporação do instrumento em 71\% dos casos (Santos Jr. e Montandon, 2011). Já na Pesquisa de Informações Básicas Municipais (Munic, 2015), elaborada pelo IBGE (2015), 74,8\% dos municípios brasileiros responderam afirmativamente para a presença de OUCs. Ainda, em pesquisa sendo atualmente desenvolvida com participação das autoras, foi realizada a leitura qualitativa dos planos diretores dos municípios com mais 100 mil habitantes e que haviam respondido afirmativamente à pesquisa Munic 2015 para a presença de OUCs. Foi encontrado que 161 de 210 municípios (76,67\%), de fato, previam o instrumento em seus planos diretores. Esses municípios englobam realidades muito diversas, como é o caso de Paragominas, no Pará, com população estimada em 111.764 habitantes e plano diretor aprovado em 2006, com a previsão de OUCs em "Área Especial de Expansão". Essa realidade socioespacial de Paragominas é muito diferente daquela vivenciada no Rio de Janeiro e em São Paulo, municípios de maior porte e que já possuem experiência com o instrumento. São justamente nessas metrópoles nacionais que se encontram os casos mais conhecidos de OUCs e que são utilizados tanto na sua crítica (Fix, 2001; Maricato e Ferreira, 2002), quanto naqueles trabalhos que enfatizam os potenciais do instrumento (Maleronka e Hobbs, 2017; Sandroni, 2008). Entretanto, essa popularização das operações pós-Estatuto impõe o questionamento sobre o efeito que uma OUC poderia ter na diversidade de cidades brasileiras. Esta pesquisa versa sobre um desses casos fora das capitais estaduais e dos municípios de maior porte, a cidade de Balneário Camboriú, em Santa Catarina.

\section{Balneário Camboriú: o desenvolvimento urbano atrelado ao turismo}

Balneário Camboriú é uma cidade do litoral norte catarinense, com aproximadamente 142.295 habitantes, segundo estimativa do IBGE para 2019. ${ }^{1}$ Apesar de ser uma cidade de médio porte, sua densidade populacional, em 2010, era de aproximadamente $2.337,67 \mathrm{hab} . / \mathrm{km}^{2}$, 
a maior do estado de Santa Catarina. A área de $45,214 \mathrm{~km}^{2}$ que já abriga essa densidade de moradores permanentes também recebe um grande número de visitantes e moradores sazonais no período da alta temporada do verão. Ou seja, o inchaço populacional que ocorre nesses meses também acaba por influenciar o traçado urbano e o padrão arquitetônico da cidade como um todo e durante todo o ano.

De fato, Balneário Camboriú, além das belezas naturais e da atividade turística, também é conhecida pelo padrão morfológico caracterizada por prédios com grande número de pavimentos, alguns dos mais altos do Brasil. As mídias populares divulgam que 8 dos 10 prédios mais altos do País entregues e/ou em construção estão localizados na cidade (Luciano, 2017). Por um lado, é importante ressaltar que, além da alta densidade demográfica, a alta taxa de domicílios desocupados também contribui para os elevados gabaritos presentes na cidade e, em especial, na Praia Central. Nesse sentido, em 2010, a taxa de domicílios ocupados era apenas $60 \%$ do total de domicílios particulares permanentes (IBGE, 2010), e isso significa um grande número de segundas residências, unidades de veraneio e/ou para investimento, como aluguel para turistas. Além disso, a legislação urbana local e o processo de urbanização da cidade contribuem para o seu skyline peculiar.

O processo de urbanização do território que hoje é delimitado como Balneário Camboriú teve início na década de 1940. Essas ocupações se concentravam em uma pequena porção da Praia Central, já sendo caracterizadas por segundas residências e especialmente para o veraneio de moradores de outras regiões do estado de Santa Catarina (Skalee, 2008). Esse processo de ocupação se intensificou com a criação de loteamentos nas décadas seguintes, e, em 1964, ocorreu a emancipação do distrito da Praia de Camboriú do município de Camboriú. A sua identidade turística se consolidou com a construção da BR-101, na década de 1970, conectando o município ao resto do País e mesmo com países vizinhos na América do Sul, que passam a "veranear" também nos balneários catarinenses.

Em 1970, com o avanço da ocupação e a emancipação do município, o primeiro Plano Diretor de Balneário Camboriú é aprovado. Naquele momento já existiam edifícios com 18 pavimentos na Praia Central. No segundo Plano Diretor da cidade, aprovado em 1989, surge a primeira restrição de gabarito na Praia Central, com limitada pela inclinação de $70^{\circ}$ do eixo da rua. Dessa forma, era a largura da via que determinava a altura das edificações, pelo cone de ventilação e insolação. Nas legislações que se sucederam, a limitação de gabarito manteve-se a mesma nas zonas mais próximas à Praia Central (ZACCS de I a III). Assim, nessas áreas de maior interesse do mercado imobiliário, o número de pavimentos é estipulado pelo eixo da via, enquanto a maioria dos outros zoneamentos mais afastados da praia tem o tradicional limite de gabarito por número de andares.

No entanto, o gabarito máximo da Praia Central salta de 18 pavimentos, na década de 1970, para 48 pavimentos, em 2013 (Beuting e Martins, 2016). Isso foi possível porque, além dos últimos ciclos de crescimento econômico, de expansão do mercado imobiliário e da própria promoção da cidade para o turismo, de fato, a atual legislação de uso e ocupação do solo é a mais permissiva até hoje. Na lei n. 2.794, de 2008, é estipulado que o coeficiente de aproveitamento máximo pode 
Figura 1 - Localização do município de Balneário Camboriú

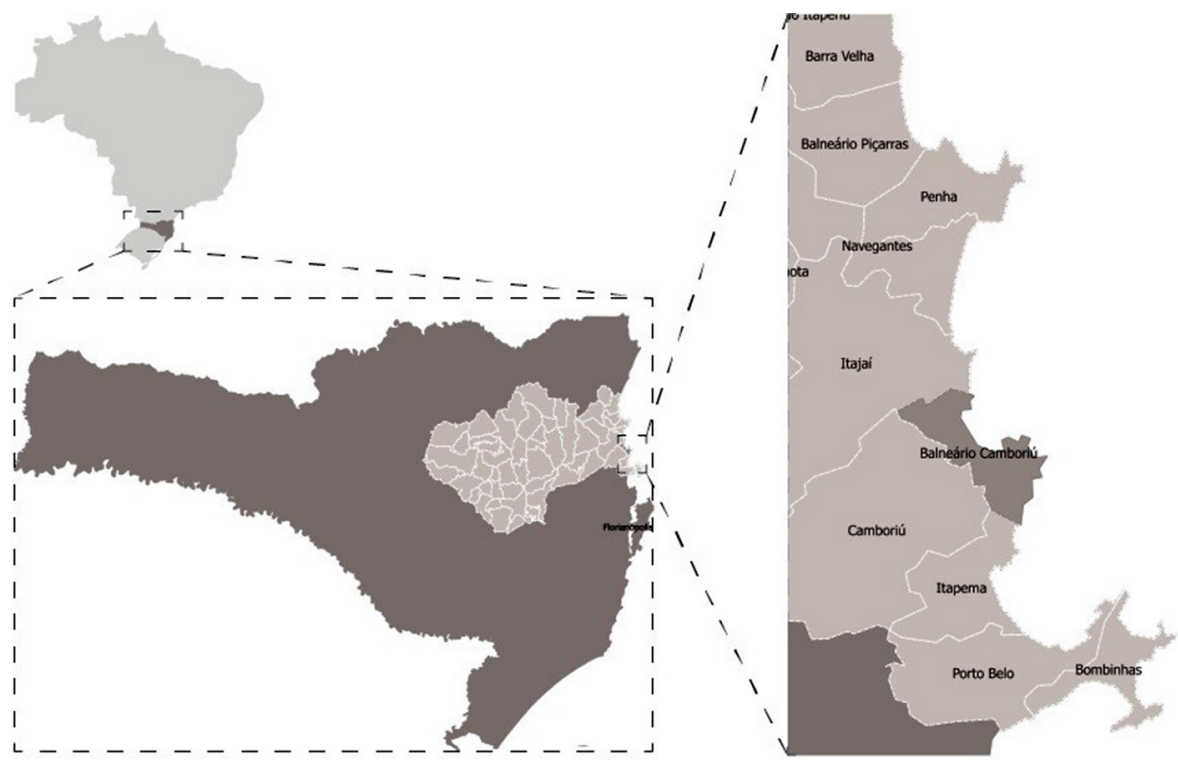

Fonte: elaboração própria com base em shapefiles do IBGE.

Figura 2 - Vista da Praia Central

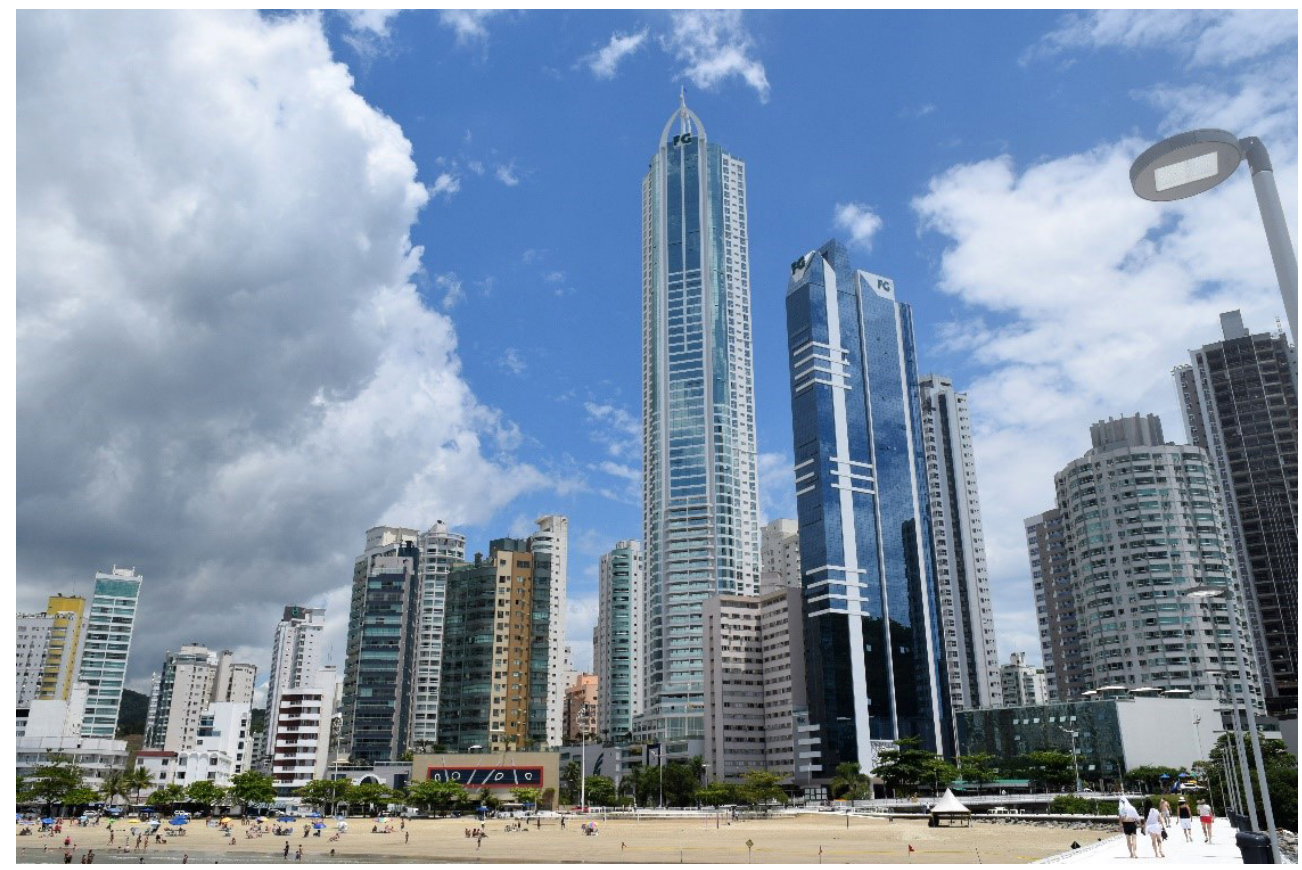

Fonte: acervo pessoal. 
atingir 6, e é prevista uma densidade máxima de 1.170 habitantes por hectare, permitindo, assim, um uso intenso do solo urbano. Ainda, atualmente, são utilizados diferentes instrumentos urbanísticos para o incremento do potencial construtivo, como a outorga onerosa e as OUCs. Esses instrumentos foram introduzidos na cidade e regulamentados pelo Plano Diretor de 2006.

O Plano Diretor de 2006 (lei municipal 2.686 de 2006) é o primeiro aprovado após o Estatuto da Cidade. É importante ressaltar que existia a obrigatoriedade de elaboração de um plano para a cidade até o final daquele mesmo ano, prazo dado pela legislação federal para adequação dos municípios, e que esse processo de planejamento deveria contar com participação popular. No entanto, de acordo com Moraes et al. (2010), o processo não tinha se iniciado até outubro de 2006, evidenciando um plano pouco participativo e sem a intenção de elucidar a população da cidade. Considerando que o plano diretor aprovado inclui instrumentos complexos do Estatuto da Cidade e que foram colocados em prática atualmente, é questionável a influência e o esclarecimento que a população local teve acerca do texto de lei e, portanto, do desenvolvimento da cidade. No entanto, ao explicar a função da legislação, a Prefeitura ressalta a redução dos custos operacionais e de investimentos, bem como a garantia da propriedade privada. ${ }^{2} \mathrm{As}$ sim, percebe-se a importância da participação do mercado imobiliário na política urbana, nos instrumentos de planejamento efetivamente implementados na cidade e que compartilham os custos e os benefícios da urbanização, como é o caso das operações urbanas.

No texto da lei do Plano Diretor, as OUCs são apresentadas de forma descritiva e são identificadas zonas (Áreas Especiais de Interesse Urbanístico) para a sua implantação ao invés de perímetros específicos. Essas áreas são: Zona de Ambiente Construído Consolidado ZACC I, II e III; Zona de Atividade Vocacionada ZAV I e II; Zona de Ocupação Restritiva - ZOR I e II; e, Zona de Ambiente Construído Secundário - Zacs. Ainda, é estipulado que não é possível realizar transferências de potencial construtivo de outras áreas para imóveis no perímetro da OUC. Já o art. 164 da mesma lei estipula que a Lei de Uso e Ocupação do Solo local estabelecerá os coeficientes mínimos, básicos, máximos e máximo para operações urbanas. Ou seja, embora seja reafirmada a necessidade de lei específica para o estabelecimento da operação, os coeficientes máximos das OUCS já são estipulados por lei que regula a cidade como um todo. Esse aspecto é importante porque o art. 162 da lei do Plano Diretor afirma que esse máximo para operações urbanas "deverá ser definido para as macrozonas que tenham disponibilidade de infraestrutura, que não modifiquem a paisagem urbana já consolidada e que não gerem grandes impactos no tráfego" (BC, 2006).

Dessa forma, o potencial adicional de construção de uma OUC pode ser utilizado em diferentes zonas urbanas e não necessariamente no seu próprio perímetro. De fato, com três OUCs já aprovadas em Balneário Camboriú, em nenhuma delas aconteceu a vinculação dos Cepacs a um projeto localizado na área da própria OUC. Pelo contrário, os seus perímetros se restringem à área de impacto das obras públicas planejadas, como será visto a seguir. Ou seja, o uso mais intensivo do solo criado pela OUC é em outras áreas da cidade, e o princípio do compartilhamento dos custos da urbanização gerada por esse uso mais intensivo 
do solo parece desvirtuado em Balneário Camboriú. Esse mecanismo de funcionamento será aprofundado a partir da experiência específica dessas operações.

\section{OUCs em Balneário Camboriú: financiando obras viárias e adensando a cidade}

Existem três OUCs já implantadas ou em implantação em Balneário Camboriú (Figuras 3 e 4). Como já mencionado, se, no Plano Diretor de 2006, é aberta a possibilidade de uso do instrumento, nenhum perímetro de OUC havia sido especificado naquele documento, apenas zonas possíveis de implementação. É na lei de zoneamento, uso e ocupação solo (lei n. 2.794/2008) que é possível encontrar a indicação de sete OUCs na cidade. Ainda, embora sejam previstas leis específicas para o estabelecimento de seus projetos, é importante ressaltar que a grande maioria das propostas presentes na lei de zoneamento indica obras de caráter viário como objetivo principal dos projetos, e, de forma mais genérica, é mencionada a utilização do instrumento também para a criação de espaços públicos de uso institucional.

Figura 3 - Localização das vias e pontos de interesse para as OUCs de Balneário Camboriú - 2020

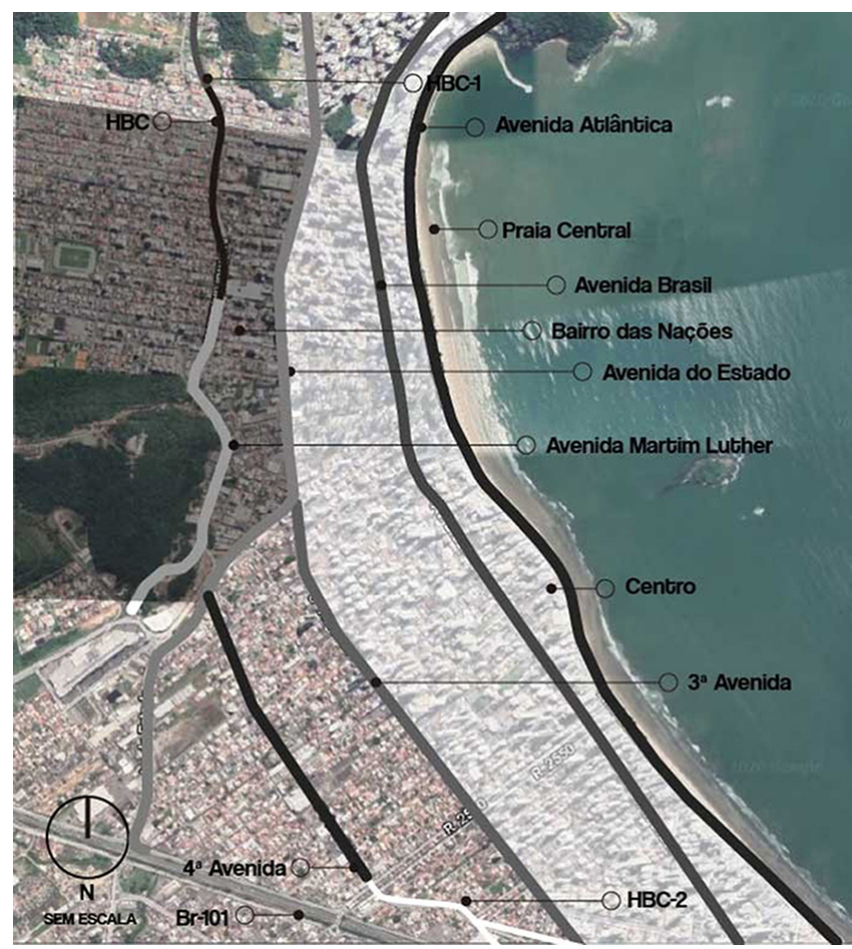

Fonte: elaboração própria a partir da legislação específica das OUCs e de imagem disponibilizada pelo geoprocessamento da Prefeitura Municipal de Balneário Camboriú. 
Figura 4 - Localização das OUCs e o zoneamento urbano - 2020

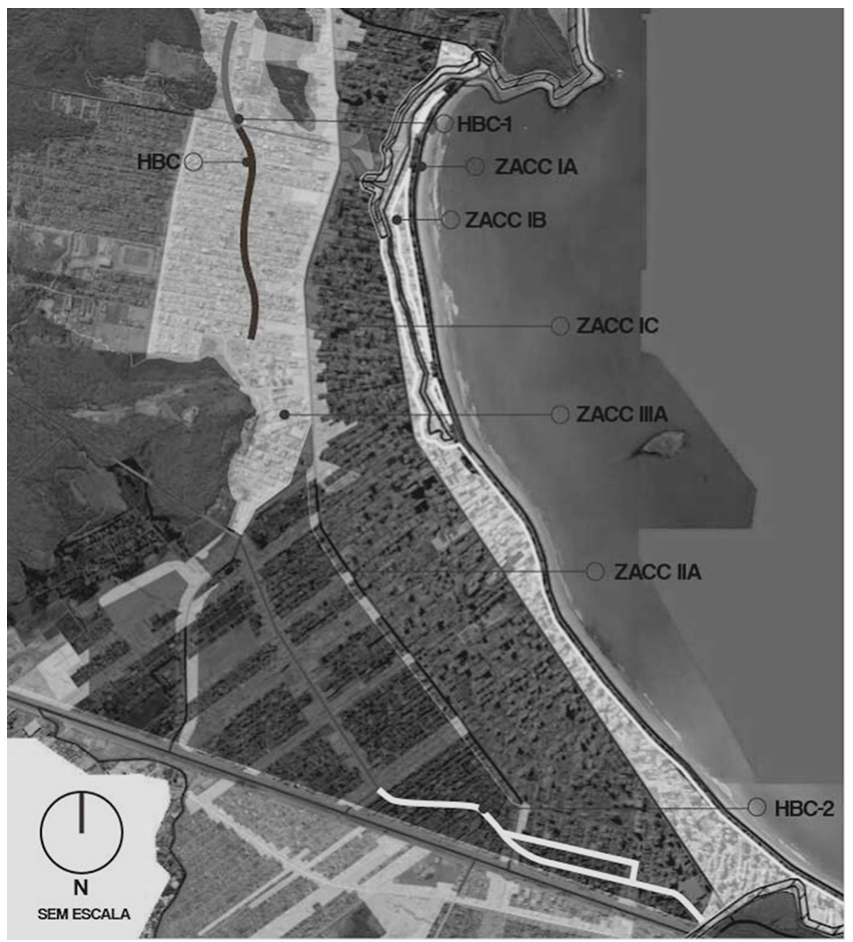

Fonte: elaboração própria a partir da legislação específica das OUCs e de imagem disponibilizada pelo geoprocessamento da Prefeitura Municipal de Balneário Camboriú.

A primeira OUC, denominada Humanizando Balneário Camboriú, é aprovada por lei específica em 25 de janeiro de 2011 (lei n. 3237/2011). Os objetivos dessa OUC, de acordo com a legislação, são: a implantação de equipamentos estratégicos; a melhoria da rede de transporte público; a implantação de espaços públicos; e a melhoria e a ampliação da infraestrutura e da rede viária municipal. As obras específicas previstas na operação são a criação da avenida Martin Luther e a implantação de iluminação, tratamento paisagístico, ciclovias e sistemas de drenagem auxiliares, bem como a criação da Praça do
Cidadão, adicionada ao plano de investimentos somente em 2018 (lei n. 4.117/2018). De fato, observando o plano de investimentos e as obras realizadas, percebe-se que a operação pouco passou da abertura da via e suas obras auxiliares. 0 próprio perímetro delimitado para a operação (Figura 5) demonstra essa situação, com a área da OUC correspondendo às edificações existentes no local previsto para a futura implantação da avenida. Não à toa, portanto, a grande maioria dos gastos da operação é proveniente da desapropriação de residências, representando mais de $90 \%$ dos valores, segundo os relatórios da Prefeitura. ${ }^{3}$ 
Figura 5 - Perímetro da OUC Humanizando Balneário Camboriú antes (2011) e após as obras (2015)
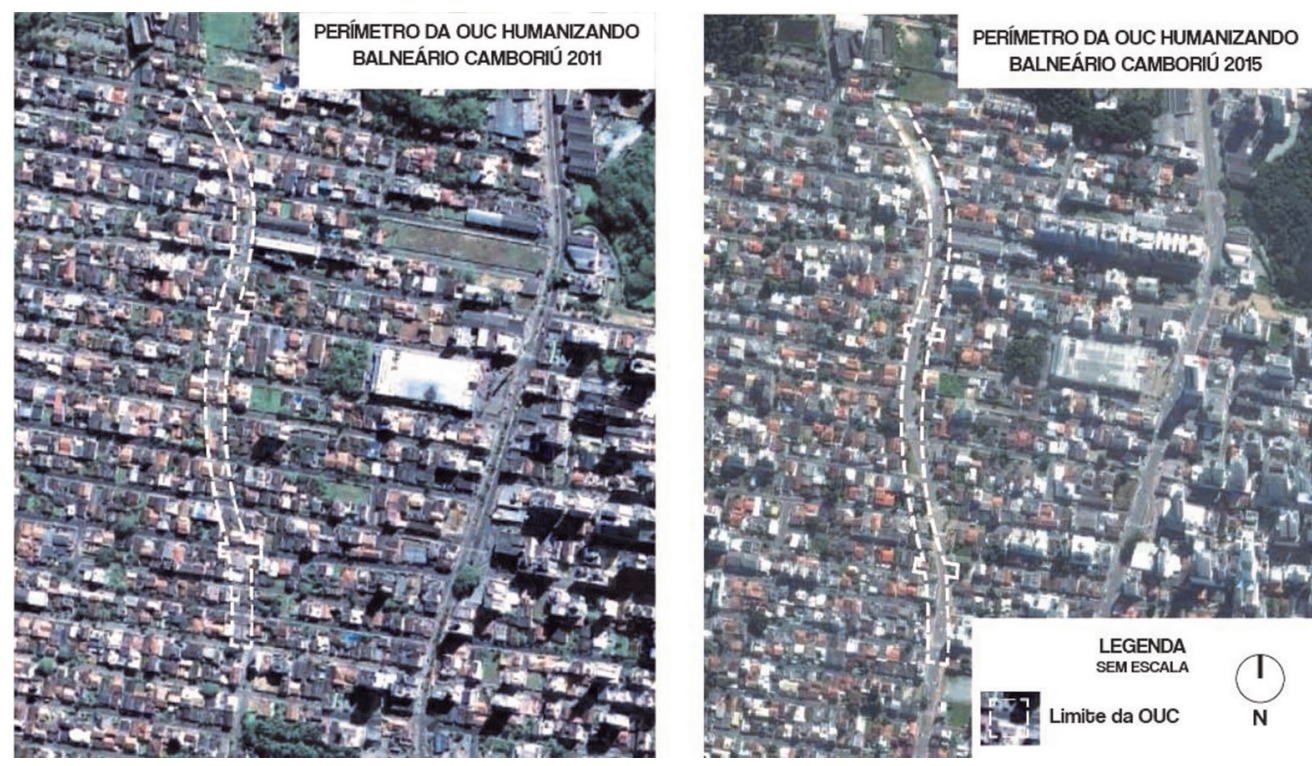

Fonte: elaboração própria a partir da lei municipal n. 3237/2011 e de imagem disponibilizada pelo geoprocessamento da Prefeitura Municipal de Balneário Camboriú.

O Bairro das Nações, no qual se localiza a operação, é de caráter predominantemente residencial com alguns comércios de pequeno porte, como lojas, farmácias e minimercados. O zoneamento vigente em todo o perímetro da OUC é de ZACC IIIA (ver Figura 4), com limitação de gabarito de 3 pavimentos. Entretanto, nenhum dos benefícios construtivos da operação foi utilizado nesse perímetro, sendo aplicados exclusivamente em outras áreas zoneadas como ZACC IA, ZACC IB e ZACC IC. Isso é possível porque o perímetro da operação diz respeito ao plano de obras previsto e à área de investimentos dos recursos arrecadados. Além disso, como já mencionado, a legislação local prevê que os benefícios construtivos estipulados pela OUC possam ser utilizados em outras áreas da cidade, segundo os coeficientes máximos estipulados pela Lei de Uso e Ocupação do Solo do município e os coeficientes de conversão de cada zona.

O financiamento da OUC é proveniente da venda de outorga onerosa que, embora denominados certificados de potencial adicional de construção, difere muito dos Cepacs utilizados em São Paulo, Rio de Janeiro e Curitiba. Nesse caso, não houve leilão e, sim, a venda direta aos interessados, de acordo com os limites previstos na lei. 0 método de cálculo é parecido nas três operações de Balneário Camboriú, como regulamentado pela lei complementar n. 3 de 5 de outubro de 2010 e baseado no custo estimado das obras.

0 potencial construtivo adicional total da operação é, então, definido pelo resultado da divisão do investimento financeiro total 
previsto para a OUC (custo) por 20\% do custo unitário básico da construção civil de Santa Catarina (CUB/SC), de dezembro de 2010, para a primeira operação, e o CUB/SC, de dezembro de 2013, para as operações subsequentes, considerados pela legislação como o "valor padrão médio de correção". ${ }^{4}$ Essa divisão gera uma área, e, em cada uma das zonas, o estoque é o produto dessa área por um fator de conversão social (denominado FCA).

O fator de conversão social procura garantir que as zonas mais valorizadas tenham o valor mais elevado de outorga, isto é, o valor do metro quadrado adicional mais caro ou que um Cepac resulte em um número menor de metros quadrados a serem construídos. Assim, na área da OUC, o FCA é igual a um, podendo ser construída toda a metragem disponibilizada pelo projeto, enquanto, nas áreas mais valorizadas da cidade, ele decresce, significando um potencial de construção menor.

A aplicação da fórmula inversa gera, portanto, o custo da outorga para o investidor imobiliário: é o produto entre a metragem requerida e o valor padrão de correção, dividido pelo FCA. As solicitações de metragem são catalogadas na Prefeitura como múltiplas do CUB/SC da data de referência da operação (dezembro de 2010 ou 2013, dependendo do projeto), mas são cobradas, utilizando-se o valor do mês de pagamento, ou seja, o CUB/ SC atualizado.

Esses cálculos para o projeto OUC Humanizando Balneário Camboriú estão descritos no Anexo 1 do decreto 6050, de janeiro de 2011. Embora o cálculo para os estoques máximos da OUC inicialmente tivesse utilizado o valor do investimento financeiro total de $R \$ 34.959 .519,07$ (custo), nesse documento é estimado que o valor do investimento seria mais de $R \$ 68$ milhões, e esse é o total considerado para o cálculo do estoque máximo da OUC e para a venda de Cepacs, resultando em um maior potencial do que o originalmente previsto. Assim, os R\$68.028.193,47 foram divididos por $207,74 \mathrm{R} \$ / \mathrm{m}^{2}$ (o valor padrão médio de correção ou $20 \%$ do CUB/SC de dezembro de 2010), gerando $327.461,65218 \mathrm{~m}^{2}$ totais nessa OUC. Para converter para cada uma das zonas, foram utilizados os FCAs e as expectativas de potencial adicional de construção e contrapartida financeira indicados na Tabela 1.

Tabela 1 - FCAs, potencial adicional e contrapartida financeira esperada na OUC Humanizando Balneário Camboriú

\begin{tabular}{l|c|c|c|c}
\hline \multicolumn{1}{c|}{ Zona } & FCA & $\begin{array}{c}\text { Potencial } \\
\text { adicional }\left(\mathrm{m}^{2}\right)\end{array}$ & $\begin{array}{c}\text { Contrapartida } \\
\text { financeira total }(\mathbf{R} \$)\end{array}$ & $\begin{array}{c}\text { Valor do } \mathrm{m}^{2} \\
\left(\mathbf{R} \$ \mathrm{~m}^{2}\right)\end{array}$ \\
\hline ZACC IA & 0,12571 & $41.165,20$ & $68.028 .193,47$ & $1.652,56$ \\
\hline ZACC IB & 0,27154 & $88.918,94$ & $68.028 .193,47$ & 765,05 \\
\hline ZACC IC Frente av. Brasil & 0,27154 & $88.918,94$ & $68.028 .193,47$ & 765,05 \\
\hline ZACC IC Meio de quadra & 0,52218 & $170.993,93$ & $68.028 .193,47$ & 397,83 \\
\hline ZACC IC Frente 3a avenida e Estado & 0,56570 & $185.245,06$ & $68.028 .193,47$ & 367,23 \\
\hline
\end{tabular}

Fonte: elaboração própria com base no Relatório de acompanhamento OUC-HBC (BC, 2013). 
De acordo com os relatórios públicos (Tabela 2), foram arrecadados $\mathrm{R} \$ 66.606 .993,47$ na OUC Humanizando Balneário Camboriú, um pouco menos do valor total estimado para as obras. No entanto, o custo efetivo foi de $\mathrm{R} \$ 40.511 .486,72$, mais próximo do previsto inicialmente e um valor bastante inferior ao arrecadado. Os $\mathrm{R} \$ 20$ milhões remanescentes foram remanejados pela lei n. 4.117, de 2014, para a segunda Operação Urbana Consorciada do município, intitulada Humanizando Balneário Camboriú 1 ou HBC-1.

A segunda OUC na cidade, Operação Urbana Consorciada HBC-1, foi aprovada pela lei n. 3.657, em 25 de fevereiro de 2014, e tem como objetivo o prolongamento da via criada pela primeira operação da cidade. Essa também é uma área majoritariamente residencial, unifamiliar e zoneada como ZACC-IIIA. As únicas obras aprovadas são de cunho viário, com adequação de passeios, drenagem e tratamento paisagístico. 0 custo da OUC está estimado em pouco mais de $\mathrm{R} \$ 38$ milhões (Tabela 3 ), sendo R\$ 20 milhões desse total já repassados da operação anterior, como mencionado. Desde 2014, a Prefeitura não apresentou nenhum relatório de acompanhamento dessa OUC, não existindo qualquer registro de venda de Cepacs até o momento.

Tabela 2 - Utilização dos recursos da OUC Humanizando Balneário Camboriú (até agosto/2019) ${ }^{5}$

\begin{tabular}{l|c|c}
\hline \multicolumn{1}{c|}{ Descrição } & Valor estimado - R\$ & Custo efetivo - R\$ \\
\hline Obras & $11.205 .020,95$ & $2.792 .098,41$ \\
Iluminação pública & $357.499,80$ & $108.465,64$ \\
Desapropriações & $54.870 .544,76$ & $37.574 .922,67$ \\
Divulgação e medidas preventivas & $173.927,96$ & $36.000,00$ \\
\hline Total geral & $66.606 .993,47$ & $40.511 .486,72$ \\
\hline
\end{tabular}

Fonte: elaboração própria com base no Relatório de acompanhamento OUC-HBC (BC, 2013).

Tabela 3 - Investimentos da OUC HBC-1 (até agosto/2019)

\begin{tabular}{l|c}
\hline \multicolumn{1}{c|}{ Descrição } & Valor estimado - R\$ \\
\hline Obras & $5.420 .566,92$ \\
Iluminação pública & $980.000,00$ \\
Desapropriações & $28.091 .288,72$ \\
Divulgação e medidas preventivas & $344.918,46$ \\
Contrapartida social & $3.449 .184,56$ \\
\hline Total geral & $38.285 .948,66$ \\
\hline
\end{tabular}

Fonte: elaboração própria com base na lei municipal n. 3.657 (BC, 2014) 
Já a Operação HBC-2, a terceira operação do município, foi aprovada em março de 2014 pela lei $n$. 3.663, apenas um mês após a aprovação da segunda OUC. O projeto também tem o caráter de obra viária. O objetivo da OUC é a ligação da 4ạ Avenida com a BR-101, principal rodovia em Santa Catarina e que realiza sua conexão com os demais estados brasileiros pelo litoral, e, mais uma vez, os principais gastos são as desapropriações de uma área de uso majoritariamente residencial, embora, por sua localização mais distante das áreas turísticas, possua também comércios e serviços de maior porte, como oficinas, marcenaria e lojas de materiais de construção. Cerca de metade do custo estimado da operação foi arrecadada com a venda de Cepacs, segundo os relatórios disponibilizados pela Prefeitura até agosto de 2019 (Tabela 4). As obras foram iniciadas em 2018 e ainda não foram finalizadas (Figura 6).

Se os projetos têm conseguido se tornar uma fonte de recursos para obras públicas, o principal aspecto das três experiências com OUCs em Balneário Camboriú a ser destacado é a utilização dos benefícios construtivos gerados pelo instrumento. É importante ressaltar que todos os recursos arrecadados com a venda de Cepacs nas OUCs de Balneário Camboriú estão sendo utilizados no perímetro do projeto, como previsto pelo Estatuto, mesmo que quase exclusivamente para obras viárias. Por outro lado, os Cepacs não estão sendo vinculados no mesmo local, sendo utilizados fora do perímetro. Portanto, as OUCs em Balneário Camboriú vão contra o previsto na lei federal o Art. $34 \S 1$ o que diz que "os certificados de potencial adicional de construção serão livremente negociados, mas conversíveis em direito de construir unicamente na área objeto da operação" (Brasil, 2001).

Como já mencionado, o plano diretor e a lei de zoneamento, uso e ocupação do solo locais permitem que os Cepacs comprados possam ser convertidos em outras áreas da cidade. Enquanto na HBC-1 não foi feita nenhuma venda de outorga ou emissão de Cepac até agosto de 2019, no primeiro projeto (OUC Humanizando Balneário Camboriú) e na HBC-2, não houve nenhuma vinculação do potencial gerado aos perímetros das

Tabela 4 - Investimentos da OUC HBC-2 (até agosto/2019)

\begin{tabular}{l|c|c}
\hline \multicolumn{1}{c|}{ Descrição } & Valor estimado - R\$ & Valor empenhado - R\$ \\
\hline Obras & $10.136 .133,65$ & 0,00 \\
Iluminação pública & $2.000 .000,00$ & 0,00 \\
Desapropriações & $81.731 .791,92$ & $28.138 .548,79$ \\
Divulgação e medidas preventivas & $903.791,80$ & 0,00 \\
Contrapartida social & $9.037 .918,04$ & $3.157 .747,09$ \\
\hline Total geral & $103.809 .635,41$ & $31.296 .295,88$ \\
\hline
\end{tabular}

Fonte: elaboração própria com base no Relatório de acompanhamento OUC-HBC2 (BC, 2016). 
Figura 6 - Perímetro da OUC HBC-2 antes (2017) e com as obras iniciadas (2019)
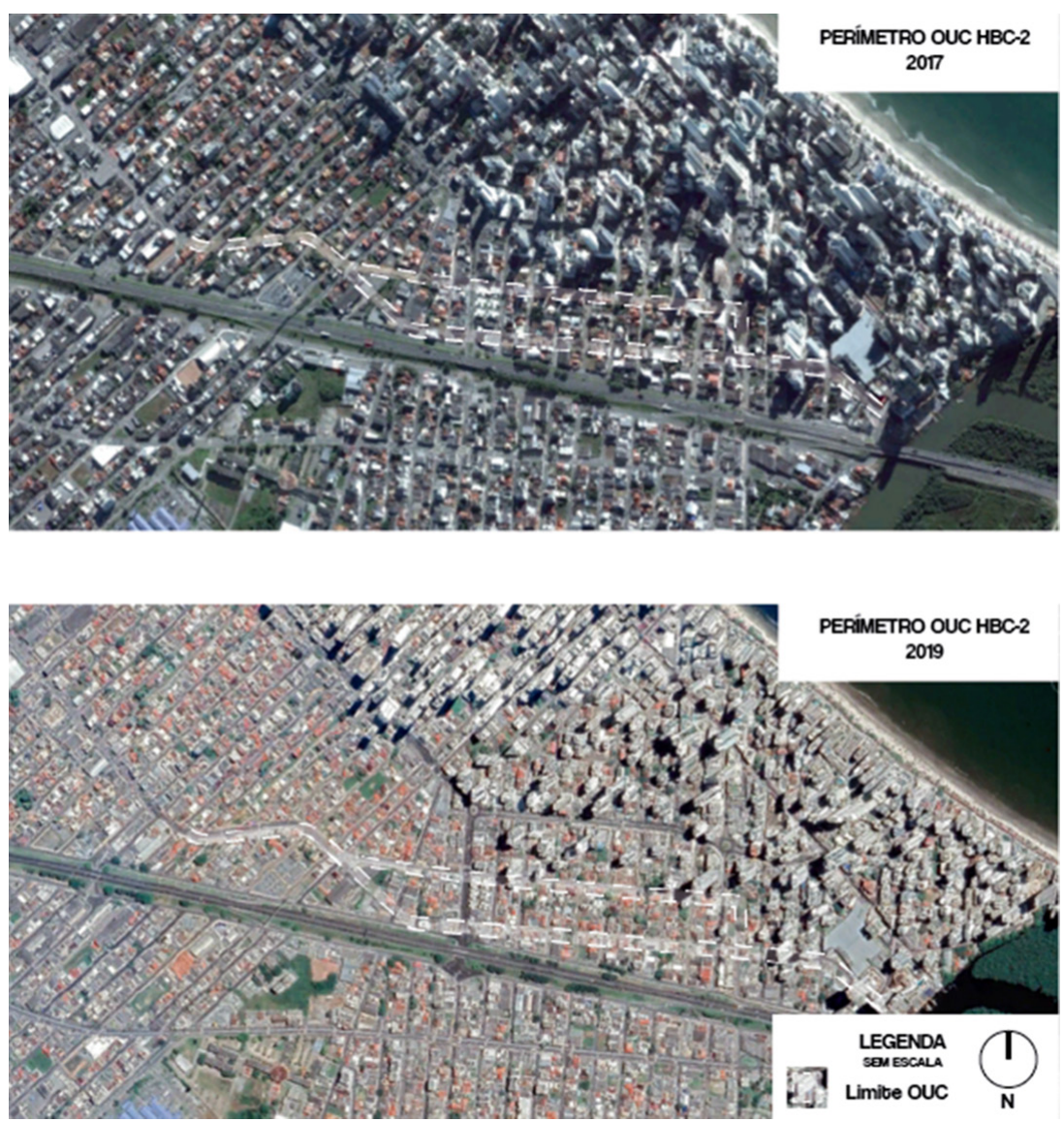

Fonte: elaboração própria a partir da legislação das OUCs e de imagem disponibilizada pelo geoprocessamento da Prefeitura Municipal de Balneário Camboriú.

operações ou mesmo à zona na qual estas se encontravam (ZACC IIA). Como se pode identificar na Tabela 5, nos dois casos, a zona que gerou a maior captura de recursos pela venda de Cepac foi a ZACC IA, que engloba a avenida Atlântica, ou seja, na beira da Praia Central e também a zona com o metro quadrado mais caro da cidade. No entanto, a zona na qual houve maior conversão do potencial adicional de construção, gerando maior metragem construída, foi a ZACC IC de meio de quadra.
Justamente, essa zona representa um novo vetor de crescimento na cidade, uma vez que as áreas mais próximas da praia já se encontram saturadas e adensadas. A ZACC IC é referente às quadras entre a avenida Brasil e a 3a Avenida, vias estruturantes da cidade e uma zona também bastante adensada. No entanto, ainda existem espaços livres, e sua localização próxima à grande área de interesse de Balneário Camboriú, a Praia Central, resulta em um alto potencial para empreendimentos imobiliários. 
Tabela 5 - Recursos arrecadados e metragem adicional por zona (até agosto/2019)

\begin{tabular}{|c|c|c|c|}
\hline Zona & Metragem adicional $-\mathrm{m}^{2}$ & Fator de conversão social & Valor-R\$ \\
\hline \multicolumn{4}{|c|}{ OUC Humanizando Balneário Camboriú } \\
\hline ZACC IA & $14.957,040$ & 0,12571 & $23.362 .436,52$ \\
\hline ZACC IB & $24.094,223$ & 0,27154 & 18.093.712,69 \\
\hline ZACC IC Frente av. Brasil & $4.394,050$ & 0,27154 & $3.547 .542,11$ \\
\hline ZACC IC Meio de quadra & $38.066,917$ & 0,52218 & $14.438 .878,90$ \\
\hline ZACC IC Frente $3^{a} \mathrm{Av}$. & $1.074,530$ & 0,56570 & $408.012,19$ \\
\hline Total & $82.586,76$ & $R \$ 59.850 .582,41$ & \\
\hline \multicolumn{4}{|c|}{ OUC-HBC 2} \\
\hline ZACC IA & $14.924,123$ & 0,12571 & $26.895 .707,24$ \\
\hline ZACC IB & $8.123,286$ & 0,27154 & $6.764 .253,46$ \\
\hline ZACC IC Frente av. Brasil & $1.523,292$ & 0,27154 & $1.463 .180,96$ \\
\hline ZACC IC Meio de quadra & $23.889,310$ & 0,52218 & $10.537 .277,76$ \\
\hline ZACC IC Frente $3^{a} \mathrm{Av}$. & $8.037,800$ & 0,56570 & $3.412 .454,01$ \\
\hline Total & $56.497,81$ & $\mathrm{R} \$ 49.072 .873,43$ & \\
\hline
\end{tabular}

Fonte: elaboração própria com base no Relatório de acompanhamento OUC-HBC 2 (BC, 2016).

Finalmente, a HBC-1 e a HBC-2 trazem novidades com relação à OUC Humanizando Balneário Camboriú. As duas legislações preveem que a contrapartida social pelos impactos gerados pela OUC estará limitada a $10 \%$ do valor total da intervenção, enquanto essas contrapartidas serão implantadas nas proximidades da operação, após a comprovação de sua necessidade por laudo ou estudo e referendada pela Comissão Especial para Operações Urbanas Consorciadas (Ceouc). A Ceouc pode ser considerada a instância de controle da operação necessariamente compartilhada com a sociedade civil, tal como imposto pelo Estatuto da Cidade. Entretanto, a sua composição é bastante discutível em termos da representatividade local.
Estabelecida em 2011 (decreto n. 6016/ 2011), a Ceouc é composta por 11 membros. Além dos seis membros do poder público executivo municipal, fazem parte: dois representantes dos corretores de imóveis, um representante do setor da construção civil (Sinduscon), um representante da Associação Regional de Engenheiros e Arquitetos (Area) e um representante da Ordem dos Advogados do Brasil (OAB), incluído pelo decreto n. 8.968, (BC, 2018). Ou seja, existe uma composição bastante direcionada aos interesses do mercado imobiliário local e que, provavelmente, influencia no tipo de investimento que pode vir a ser realizado com os recursos arrecadados, considerando-se, ainda, a imposição de as contrapartidas sociais serem aprovadas pela 
mesma Comissão e limitadas a $10 \%$ do valor total da intervenção. 0 grupo gestor, com a mesma composição, atua nas três operações da cidade, tal como definido por suas leis específicas: leis municipais n. 3.237 (BC, 2011a), n. 3.657 (BC, 2014a) e n. 3.663 (2014b). A Ceouc também auxilia nas atividades do Fundo Especial de Transferência de Potencial Construtivo (FETPC), que administra a utilização dos recursos gerados pelas OUCs. O FETPC está vinculado à Secretaria de Planejamento Urbano do município, e os seus membros são todos representantes do poder público.

\section{Considerações finais}

Ainda há muito o que ser explorado sobre os efeitos práticos do Estatuto da Cidade nos municípios brasileiros. Embora existam experiências pioneiras com diversos de seus instrumentos, a legislação federal normatizou a utilização deles e acabou por disseminá-los em território nacional. Assim, se a obrigatoriedade do plano diretor para os municípios com mais de vinte mil habitantes, entre outros critérios, expandiu a sua elaboração nos municípios brasileiros, a experiência com alguns dos instrumentos do Estatuto em cidades de pequeno e médio porte ainda é pouco analisada. Esse é o caso das OUCs, objeto de estudo deste trabalho.

A possibilidade de realização de uma agenda pública com baixos custos para os cofres municipais bem como a flexibilização dos índices construtivos para novos empreendimentos do mercado imobiliário têm feito as OUCs terem grande aceitação por parte das prefeituras e dos agentes privados. Portanto, pesquisas têm demonstrado que a maioria dos planos diretores municipais inclui o instrumento. Se os casos mais analisados são aqueles localizados em metrópoles nacionais e capitais estaduais e com resultados bastante polêmicos, ainda pouco é explorado sobre a implantação das operações urbanas em cidades com menor porte populacional e econômico.

No Balneário Camboriú, podemos destacar que as três OUCs implantadas na cidade até 2019 possuem obras viárias como o principal objetivo a ser atingido. Fora uma praça de pequeno porte adicionada posteriormente a um dos projetos, os objetivos previstos pelo Estatuto da Cidade de melhorias sociais e/ou valorização ambiental são praticamente inexistentes como resultados dessas OUCs até o presente momento. De fato, a legislação dos dois últimos projetos aprovados limita a contrapartida social pelos impactos gerados pela OUC em $10 \%$ do valor total da intervenção. Ainda, essas contrapartidas sociais serão implantadas somente após a comprovação de sua necessidade por laudo ou estudo e seu referendamento pela Ceouc. Essa comissão, a mesma para todos os casos de OUC na cidade, representa o controle compartilhado com a sociedade civil, como exigido pelo Estatuto da Cidade. No entanto, os representantes são, além de membros do poder executivo municipal, relacionados aos setores do mercado imobiliário e da OAB. Sem qualquer representação de moradores ou movimentos populares, é bastante improvável que esses projetos possuam outros objetivos que representem maior interesse coletivo.

Embora a venda de potencial adicional de construção com a possibilidade de utilização fora do perímetro das OUCs tenha sido atrativa para o mercado imobiliário, a OUC transformou-se em um mecanismo de 
arrecadação de recursos para o financiamento de obras públicas aprovadas pela lei específica da OUC. Nesse sentido, a Prefeitura vem cumprindo o Estatuto da Cidade ao utilizar os recursos gerados somente no perímetro do projeto. No entanto, esse funcionamento desvirtua os princípios do solo criado e da separação do direito de propriedade do terreno do direito de construir sobre ele. Assim, o pagamento pelo potencial adicional de construção gerado por essas OUCs resulta na densificação de outras áreas da cidade e não naquelas em que, de fato, se localizam as obras do projeto, indo contra o previsto na lei federal. Como resultado, a área que gerou mais recursos financeiros é a zona mais valorizada e com edificações com maior número de pavimentos na cidade (a Praia Central), enquanto a utilização da maior parte do potencial construtivo gerado pelas OUCs tem se dado, justamente, no novo vetor de desenvolvimento imobiliário da cidade, resultando no maior adensamento de metros quadrados construídos. Mesmo que exista um fator de conversão para que as áreas mais valorizadas da cidade possuam uma outorga mais cara, as fórmulas são calculadas a partir de uma porcentagem de um índice já abaixo do valor de mercado do metro quadrado ou mesmo de sua construção. Para o investidor imobiliário, as OUCs viraram um mecanismo para construir edificações maiores com um custo baixo e, portanto, obter mais lucro.

Como conclusão, a experiência de Balneário Camboriú pouco difere das OUCs em outras cidades brasileiras, trazendo à tona uma falta de equilíbrio na parceria público- privada em que os principais benefícios coletivos dos projetos são obras viárias e os principais beneficiados são os agentes do mercado imobiliário. Nesse caso, no entanto, o aspecto mais destacado é o seu mecanismo de funcionamento que desvirtua o princípio do solo criado com a possibilidade de utilização do potencial construtivo gerado pelas OUCs em outras zonas da cidade, atendendo aos interesses do mercado imobiliário por novos vetores de desenvolvimento. Em uma cidade já conhecida pelas edificações com grande número de pavimentos e de unidades habitacionais vazias, aguardando o veraneio e/ou aluguel, as operações urbanas pouco têm servido para atingir os objetivos mais amplos expostos no Estatuto da Cidade, ou seja, aqueles voltados para o cumprimento da função social da cidade e sua gestão democrática.

\section{[I] https://orcid.org/0000-0002-1042-8743}

Universidade Federal de Santa Catarina, Centro Tecnológico, Departamento de Arquitetura e Urbanismo. Florianópolis, SC/Brasil.

marina.siqueira@ufsc.br

\section{[II] https://orcid.org/0000-0003-2918-6307}

Pesquisadora autônoma. Florianópolis, SC/Brasil. carolinaslschleder@gmail.com 


\section{Notas}

(1) Dados de Balneário Camboriú disponibilizados pelo IBGE. Disponível em: <https://cidades.ibge. gov.br/>. Acesso em: 7 jul 2020.

(2) Texto disponível em: https://www.bc.sc.gov.br/plano-diretor.cfm, acesso em: 7 jul 2020. Embora o site seja sobre o Plano Diretor de Balneário Camboriú, não foi possível, ao longo desta pesquisa, baixar a lei ou a cartilha por essa via, demonstrando a falta de transparência e dificuldade de acesso ao documento pela população.

(3) Disponível em: https://www.bc.sc.gov.br/conteudo.cfm?caminho=planejamento-urbano-e-gest. Acesso em: 7 jul 2020.

(4) Custo Unitário Básico da Construção Civil (dezembro de 2010): R\$1.038,72; custo Unitário Básico da Construção Civil (dezembro de 2013): R\$1.309,57.

(5) É importante destacar que, após pesquisa on-line, contato por telefone e e-mail, até julho de 2020, a Prefeitura de Balneário Camboriú não disponibilizou dados mais atualizados acerca das OUCs da cidade.

\section{Referências}

BASSUL Jr., J. R. (2002). Reforma urbana e Estatuto da Cidade. EURE, v. 28, n. 84, pp. 133-144. Disponível em: http://www.scielo.cl/scielo.php?script=sci_arttext\&pid=S0250-71612002008400008\&Ing=e s\&nrm=iso. Acesso em: 8 abr 2011.

BC - BALNEÁRIO CAMBORIÚ (2006). Lei n. 2868, de 19 de dezembro de 2006. Dispõe sobre a revisão do plano diretor do município de Balneário Camboriú. Balneário Camboriú.

(2011a). Lei Municipal n. 3.237, de 25 de janeiro de 2011. Cria e regulamenta diretrizes urbanísticas por meio de instrumento de política urbana denominada de operação urbana consorciada "humanizando Balneário Camboriú", conforme lei complementar n. 003/2010, e dá outras providências. Balneário Camboriú.

(2011b). Decreto n. 6.016, de 17 de janeiro de 2011. Cria e nomeia membros para compor a comissão especial de operações urbanas consorciadas, e dá outras providências. Balneário Camboriú.

(2011c). Decreto n. 6.050, de 18 de fevereiro de 2011. Regulamenta a lei n. 3.237, de 25 de janeiro de 2011, que aprovou a operação urbana consorciada humanizando Balneário Camboriú (OUC-HBC), no que se refere aos aspectos urbanísticos e aos procedimentos a serem aplicados aos empreendimentos que fizerem uso dos benefícios nela previstos. Balneário Camboriú.

(2013). Relatório de acompanhamento OUC-HBC 2013, de 15 de agosto de. Balneário Camboriú, 2013. Disponível em: https://www.bc.sc.gov.br/conteudo.cfm?caminho=planejamento-urbanoe-gest. Acesso em: 27 jul 2019. 
BC - BALNEÁRIO CAMBORIÚ (2014a). Lei Municipal n. 3.657, de 25 de fevereiro de 2014. Cria e regulamenta diretrizes urbanísticas por meio de instrumento de política urbana denominada de operação urbana consorciada humanizando Balneário Camboriú 1 (OUC-HBC1), conforme a lei complementar n. 003/2010, e dá outras providências. Balneário Camboriú.

(2014b). Lei Municipal n. 3.663, de 28 de março de 2014. Cria e regulamenta diretrizes urbanísticas por meio de instrumento de política urbana denominada de operação urbana consorciada humanizando Balneário Camboriú 1 (OUC-HBC2), conforme a lei complementar n. 003/2010, e dá outras providências. Balneário Camboriú.

(2016). Relatório de acompanhamento OUC-HBC 2 2016, de 31 de julho de. Balneário Camboriú. Disponível em: https://www.bc.sc.gov.br/conteudo.cfm?caminho=planejamento-urbano-e-gest. Acesso em: 27 jul 2019.

(2018). Decreto n. 8.968, de 7 de junho de 2018. Altera dispositivo do decreto municipal n. 6.016, de 17 de janeiro de 2011, que "Cria e nomeia membros para compor a Comissão Especial de Operações Urbanas Consorciadas", e dá outras providências". Balneário Camboriú.

BEUTING, A.; MARTINS, B. C. V. (2016). Evolução histórica da verticalização de Balneário Camboriú: Orla da Praia e área central da cidade In: SEMINARIO INTERNACIONAL DE INVESTIGACIÓN EN URBANISMO. Anais... Barcelona-Balneário Camboriú.

BRASIL (2001). Lei n. 10257, de 10 de julho de 2001. Regulamenta os arts. 182 e 183 da Constituição Federal, estabelece diretrizes gerais da política urbana e dá outras providências. Brasília, Câmara dos Deputados.

FIX, M. (2001). Parceiros da exclusão. Duas histórias de construção de uma "Nova Cidade" em São Paulo: Faria Lima e Água Espraiada. São Paulo, Boitempo.

IBGE - Instituto Brasileiro de Geografia e Estatística (2010). Censo 2010. IBGE.

(2015). Pesquisa de Informações Básicas Municipais - MUNIC. IBGE. Disponível em: https:// www.ibge.gov.br/estatisticas/sociais/educacao/10586-pesquisa-de-informacoes-basicasmunicipais.html?=\&t=o-que-e. Acesso em: 10 dez 2019.

LUCIANO, A. (2017). Dubai brasileira em Santa Catarina reúne os prédios mais altos do país. Gazeta do Povo. Disponível em: https://www.gazetadopovo.com.br/vida-e-cidadania/dubai-brasileiraem-santa-catarina-reune-os-predios-mais-altos-do-pais-0zy3kukf0j2bziqx71qm0ts64/. Acesso em: 8 ago 2019.

MALERONKA, C.; HOBBS, J. (2017). Operações urbanas: o que podemos aprender com a experiência de São Paulo? Notas técnicas IDB-TN-1355.

MARICATO, E. (2000). "As ideias fora do lugar e o lugar fora das ideias: planejamento urbano no Brasil". In: ARANTES, O.; VAINER, C.; MARICATO, E. (orgs.). A cidade do pensamento único: desmanchando consensos. Petrópolis, Vozes.

MARICATO, E.; FERREIRA, J. S. (2002). “Operação Urbana Consorciada: diversificação urbanística participativa ou aprofundamento da desigualdade?”. In: OSÓRIO, L. M. (org.). Estatuto da Cidade e reforma urbana: novas perspectivas para as cidades brasileiras. Porto Alegre, Sérgio Antonio Fabris.

MORAES, S. et al. (2010). Capacitação e mobilização: a perspectiva da participação cidadã no Plano Diretor de Balneário Camboriú (SC), Brasil. Revista da gestão costeira integrada. Lisboa, Associação portuguesa de recursos hídricos, v. 10, n. 4, pp. 567-587. 
OSÓRIO, L. M. (2002). “Direito de superfície”. In: OSÓRIO, L. M. (org.). Estatuto da cidade e reforma urbana: novas perspectivas para as cidades brasileiras. Porto Alegre, Sergio Antonio Fabris.

ROLNIK, R. (2002). "Outorga onerosa e direito de construir". In: OSÓRIO, L. M. (org.). Estatuto da cidade e reforma urbana: novas perspectivas para as cidades brasileiras. Porto Alegre, Sergio Antonio Fabris.

SANDRONI, P. (2008). O Cepac (Certificado de Potencial Adicional de Construção) como instrumento de captação de mais valias urbanas e financiamento de grandes projetos urbanos. Relatório de Pesquisa GV. Disponível em: http://gvpesquisa.fgv.br/sites/gvpesquisa.fgv.br/files/publicacoes/ Paulo\%20sandroni\%20- \%20Cepac08.pdf. Acesso em: 5 fev 2012.

SANTORO, P. (2004). Gestão social da valorização da terra. São Paulo, Instituto Pólis.

SANTOS JUNIOR, O. A. dos; MONTANDON, D. T. (orgs.) (2011). Os Planos Diretores Municipais Pós-Estatuto da Cidade: balanço crítico e perspectivas. Rio de Janeiro, Letra Capital, Observatório das Cidades e IPPUR/UFRJ.

SKALEE, M. (2008). Construção e apropriação do espaço público: estudo do traçado urbano do Centro de Balneário Camboriú. Dissertação de mestrado. Florianópolis, Universidade Federal de Santa Catarina.

SMOLKA, M. (2014). Recuperação de mais-valias fundiárias na América Latina: políticas e instrumentos para o desenvolvimento urbano. Lincoln Institute of Land Policy. Disponível em: https://www. lincolninst.edu/sites/default/files/pubfiles/recuperacao-mais-valias-fundiarias-full_0.pdf. Acesso em: 24 abr 2020.

VILLAÇA, F. (1999). “Uma contribuição para a história do planejamento urbano no Brasil”. In: DEÁK, C.; SCHIFFER, S. R. (orgs.). O processo de urbanização no Brasil. São Paulo, Edusp.

Texto recebido em 4/ago/2020

Texto aprovado em 12/out/2020 